
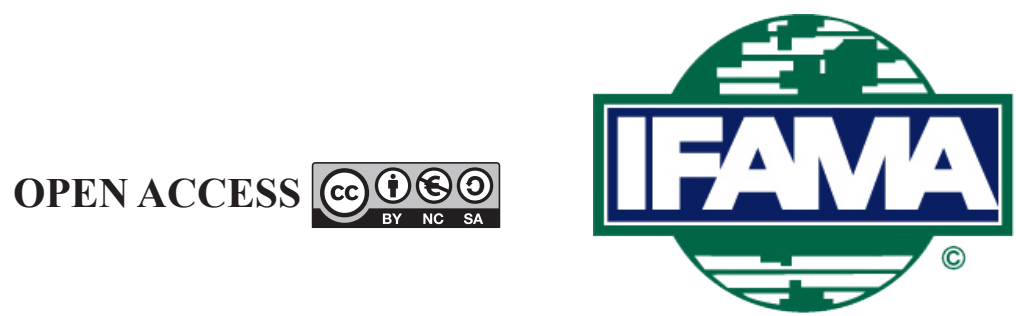

International Food and Agribusiness Management Review

Volume 21 Issue 5, 2018; DOI: 10.22434/IFAMR2017.0023

Received: 22 February 2017 / Accepted: 5 November 2017

\title{
King's Hawaiian: managing the supply of aloha spirit for every household, every day
}

Special issue: Teaching case studies in food and agribusiness management

\section{CASE STUDY}

\author{
Brian A. Bourquard ${ }^{\circledR a}$ and Allan W. Gray ${ }^{b}$ \\ ${ }^{a}$ PhD Candidate and Research Assistant, and ${ }^{b}$ Professor of Agricultural Economics, Department \\ of Agricultural Economics, Purdue University, 403 W. State Street, Lafayette, IN 47901, USA
}

\begin{abstract}
King's Hawaiian has been family owned for more than six decades, and the 'aloha spirit' runs deep. But, rapid growth in recent years has exposed serious challenges. From production inefficiencies to supply chain disruptions, management recognizes the need to rapidly evolve their family business to a professionally managed one. Their relationship-based supply chain worked for a family firm, but will this approach continue to work as they expand rapidly? A disruption in their egg supply exposed the firm to risks they never anticipated. Now, they are rethinking their entire supply chain, including their most important raw material: flour. How can they strategically manage their raw material needs while sustaining double-digit growth? How do they identify and mitigate risks in their chain? King's Hawaiian knows its success is in its supply chain, including their unique delivery model. Getting this right is critical to their mission: to deliver their aloha spirit to every household, every day.
\end{abstract}

Keywords: supply chains, strategy, food manufacturing

JEL code: L66, M10, Q13

\footnotetext{
(1)Corresponding author: bbourqua@purdue.edu
}

A teaching note has been prepared for this case study. Interested instructors at educational institutions may request the teaching note by contacting the author or IFAMA. 


\section{Introduction: King's Hawaiian}

It was a beautiful Monday morning in the Spring of 2015 and Steve Richards had managed to miss most of the traffic on the notorious Los Angeles I-405. Steve was thinking about the week ahead when his phone buzzed with a call from Dan Raatjes. As the chief financial officer for King's Hawaiian, it was not unusual for Steve to get calls from Dan, the vice president of operations, but on a Monday morning Dan would usually have waited until Steve arrived at the office for their quick, informal weekly planning meeting. 'I just had phone calls from our egg suppliers in Iowa,' Dan said. 'They wanted us to know their farms were just hit with avian flu. There's no way they can deliver all the eggs. We are looking at a major supply problem'. Just last year Steve and Dan had tackled a butter crisis as dairy prices skyrocketed; now eggs? Steve had been hoping for a routine week to spend some time on long-term plans for the company, not to put out fires.

'I'll be at the office in a few minutes,' Steve replied. 'Let's get Torrey (Nelson, director of baking science) to meet with us. Somebody's probably getting a trip to the Midwest'.

As he exited the interstate, Steve's mind started working on the issues Dan had raised regarding the new problem: what people need to be involved, who should be at the top of the call list, what were the implications for production, and how would this impact the Georgia operations? He pulled into the parking lot and saw Mark's new Porsche, the only flashy luxury the company's owner and chief executive officer CEO had permitted himself. It was good that Mark was always in early, Steve thought. Mark's father, Robert Taira, had founded the Hawaiian Foods company more than 60 years ago, and this crisis was just one more step in its transition to a national company. Today, the company focused on making sweet Hawaiian bread products, with plans to introduce additional product lines in the near future. Steve was sure that between his own attention to detail, Mark's attention to production quality, and Dan's problem-solving abilities, they would get through the avian influenza crisis. More than that, Steve knew that if they managed it well, they could take a crisis and make it into an opportunity. The next few weeks, Steve thought, could be very interesting. After all, one of the greatest challenges faced by the quickly growing company was managing and strategizing the raw material supply chain.

\section{Transitions: from founding to professional management}

Robert founded King's Hawaiian in 1950 in Hilo, Hawaii, USA, and for more than six decades and two generations, the company has exemplified Robert's 'aloha spirit'. Today, Mark works tirelessly to grow the company and prepare the third generation of family owners for the task of running what they hope will be a billion-dollar organization. 'I'm second generation, but we have third and fourth generations who could grow up in the business,' Mark said. 'My work today is to lay the foundation for the future' (Gorton and Malovany, 2014).

Driven by Mark and his family's legacy, the corporate culture of King's Hawaiian goes much deeper than the ubiquitous Hawaiian shirts the staff often wear. His mission is to build an enduring values-driven company that lives the aloha spirit of compassion, friendship, and opportunity. King's Hawaiian is creating the Hawaiian foods category. For Mark and his family, it's all about sharing their culture with American households every day, through irresistible, indulgent Hawaiian foods.

The history of Hawaiian food is unique and complex. Hawaiian culture has been influenced extensively by several periods of immigration to the Hawaiian Islands, starting with ancient Polynesians over 1,500 years ago. The Polynesians introduced many important foods and methods, including taro root and kalua, or pit cooking. In 1778, Europeans arrived on the islands and shortly after founded sugarcane plantations and planted pineapple, increasing the need for labor. Between the $19^{\text {th }}$ and $20^{\text {th }}$ centuries, the Hawaiian Islands attracted immigrants from various Asian cultures, particularly from Japan and the Philippines. Additionally, during this time, many immigrants from Portugal arrived, bringing with them traditional sweet bread recipes. 
The original Hawaiian sweet bread recipes made by King's Hawaiian today are descendant from these early influences on island culture and cuisine.

King's Hawaiian moved from Hawaii to California in 1977 with the opening of a 24,000 square foot commercial bakery in Torrance. There the company produced its original Hawaiian round bread and in 1983 it introduced its mainstay twelve pack of Original Hawaiian Sweet dinner rolls (Figure 1), now the most popular dinner rolls in the US. In the 1990s, King's Hawaiian expanded its California production facility by 40,000 square feet, but by 2004 the company needed more space. They opened a fully-automated, 150,000 square foot production facility and corporate headquarters in Torrance. The new facility expanded production capacity by a factor of five; but, annual growth has been relentless, exceeding $15 \%$ for seven of the last ten years.

The management team realized in 2007 that they needed to plan for the future through expanded capacity and a broader national footprint. In 2010, the company acquired 20 acres of land north of Atlanta in Oakwood, Georgia, USA, and by 2011 they opened a 120,000 square foot production facility there. At the time, management believed they would have adequate capacity through 2015; however, because of fast growth, they opened an additional 120,000 square foot facility adjacent to the original Oakwood facility in late 2014.

King's Hawaiian expects to grow by $15-18 \%$ in 2015 (Figure 2), and the executive leadership team believes the company will generate more than $\$ 1$ billion in annual revenues within a decade, a huge accomplishment in the slow growth, competitive $\$ 42$ billion US Bread industry. In the late-2000s, the challenges of such fast growth threatened to overwhelm the family-run firm. Mark's leadership and vision had created a household brand, but he determined he needed help. To make it to the next level, King's Hawaiian needed an expanded and experienced leadership team.

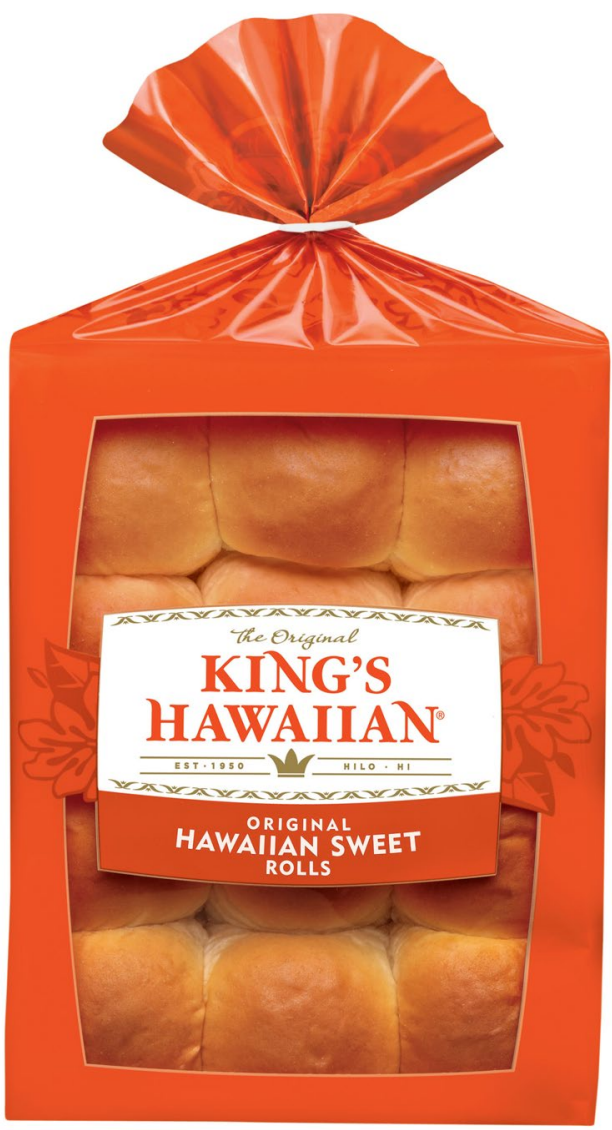

Figure 1. King's Hawaiian sweet rolls. 


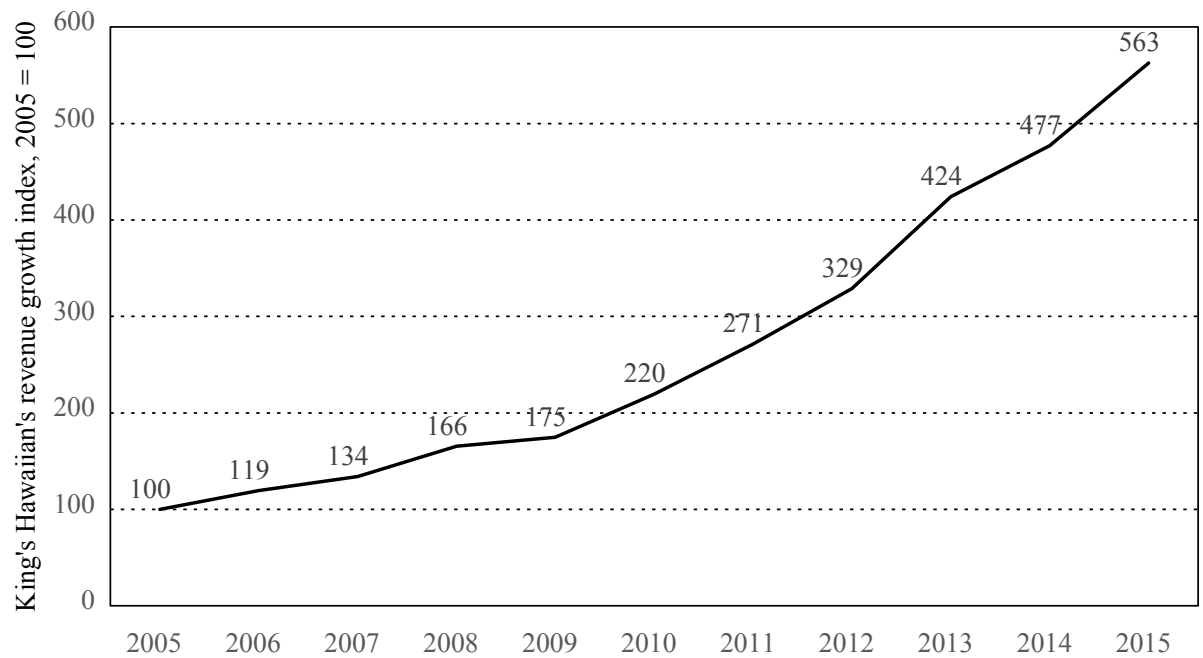

Figure 2. King's Hawaiian revenue growth.

In 2006, Mark was introduced by his banking team to John Linehan, who would become a longtime advisor and colleague, to help him chart the course forward for King's Hawaiian. John helped Mark prepare the company to make the transition from a family-run, 60-year-old start-up, to a professionally managed firm. 'We had to figure out the five-year plan so that we could start answering the question: where is King's Hawaiian in its 100-year journey?' John said.

By 2008, Mark had convinced John to be his executive vice president of strategy and development. John brought decades of executive business and consulting experience to the company, with significant experience in consumer packaged goods, and his first goal was to assemble a top-tier leadership team. In 2012, John and Mark hired Dan Raatjes as vice president of operations, followed in 2013 by Steve Richards as chief financial officer. Dan, who's background was in housing development and technology, made it his primary objective to develop multiple sources for the four major raw materials: wheat flour, butter, sugar, and eggs. Until 2012, King's Hawaiian had only one supplier for each of the four major production inputs, which posed serious risks to its supply chain.

Steve, who came to King's Hawaiian from the technology industry, was instrumental in negotiating the financing for the Oakwood, Georgia, facilities. John, Steve, and the finance team worked with GE Capital to secure more than $\$ 100$ million for the company's expansion plans, and King's Hawaiian spent more than \$45 million on the original Oakwood facility. Additionally, King's Hawaiian worked with the State of Georgia and Lanier Technical College to establish a training program for new employees. By the end of 2015, officials expect the company to employ more than 400 workers and produce half of the output at the Georgia facility. Considering the future of the Georgia operations, John notes that, 'we are not a bread company. We're a Hawaiian foods company that happens to make bread now. It is very possible that we could be making other foods on this property' (Gill, 2011). The new production facilities, fast growth, and unique challenges are reflective of the firm's transition to professional management and long-term outlook.

The shift from a family-run to professionally-managed firm is also reflected in the transition from an artisanal to a scientific attitude toward production. King's Hawaiian's primary competition in the industry came from in-store bakeries, and to compete at a premium price in the grocery store channel the company needed to provide a superior product. The Taira family is exacting in their quality expectations - losing as much as $10-15 \%$ of production to maintain quality. They use only high quality raw materials, and never use substitutes, such as oil, margarine, or corn syrups. They regard King's Hawaiian as an artisanal Hawaiian foods company, a difficult position to defend in a commodity-driven industry, particularly when consolidation has reduced national competitors from eight to three in the past fifteen years. Torrey Nelson started working for the King's Hawaiian Bakery and Restaurant as a student fifteen years ago. Not only is his longevity a 
testament to the company's family culture, he has been instrumental in developing the scientific mindset, qualifying new raw materials sources, and creating quality measures for the production lines. While Dan sought new sources for the major supplies, Torrey tested them in King's Hawaiian's production processes to ensure consistent high quality.

With the transition from a 60-year-old start-up to a maturing, high-growth company underway, and with the expanded leadership team (Figure 3), Mark and John have had time to think about where King's Hawaiian is on its 100-year journey. Together, they articulated three major goals: to build a national brand; to develop new Hawaiian food products, such as sauces, and enter new markets; and to continue creating more efficient operations while maintaining the high-quality standards for which they are famous. These goals align well with the industries primary key success factors: brand establishment, differentiated products, and cost control. At times, the challenges appear daunting. King's Hawaiian's marketing has been extremely effective at increasing sales. Current household penetration is more than $25 \%$ and the firm has a goal to exceed $45 \%$ over the next decade. Additionally, sales of King's Hawaiian products are highly seasonal, spiking around the holiday season, Easter, and summer - a trend reflected by a consumer purchase frequency of three to four times per year. Over the next decade, their goal is to smooth out consumption and increase the purchase frequency to between six and seven. While marketing can drive demand, it cannot solve the supply chain and production challenges associated with fast growth.

King's Hawaiian's primary ingredients are commodities, but the company has stringent specifications, which makes sourcing challenging. Dan and Torrey have spent countless hours locating and qualifying new ingredient suppliers to keep up with growth and mitigate supply chain risks. Meanwhile, Steve and Dan's teams worked tirelessly with the sales and marketing teams to forecast input and output demands and manage contracts. Dan and Steve have worked hard to develop and maintain relationships with suppliers, both old and new, and the relationship focus has helped the firm overcome significant challenges. As King's Hawaiian grows, the executive team continues to uphold the Taira family's focus on relationship building that helped the company achieve its success.

Mark and his executive team are working to build a company that delivers aloha spirit and irresistible Hawaiian foods to every household, every day. As Steve thinks about the future of King's Hawaiian, he acknowledges there are serious challenges ahead. How can a firm with such specific raw material needs find reliable sources while sustaining double-digit growth? How do they identify and mitigate risks in their supply chain? What kinds of contracts are most effective and how does the company maintain the many relationships it needs going forward? How can King's Hawaiian continue to deliver on its quality promise while reducing waste and containing expenses? What does the company need now to be a billion-dollar brand in ten years?

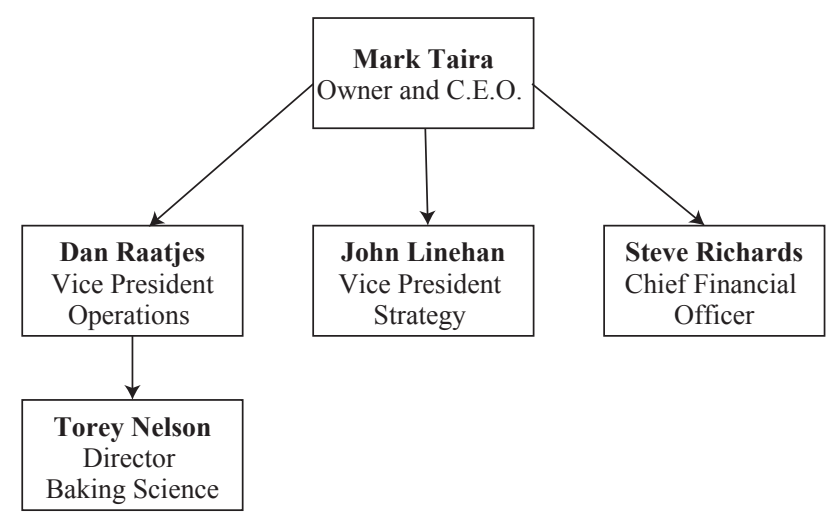

Figure 3. King's Hawaiian organizational chart. 


\section{The United States bread industry}

US bread-products are a slow growth industry, at only $1.7 \%$ annualized growth over the preceding five years, and expected annualized growth of only $1.1 \%$ through 2020. Fresh and frozen breads account for just over $50 \%$ of total industry revenues of $\$ 42$ billion. The bread product market is mature, generally unconcentrated, and competitive (Yucel, 2015). While consolidation is occurring at the large commercial operator level, local retail producers are unconcentrated and geographically distributed.

There are three primary suppliers of bread in the US marketplace: large commercial bakeries, in-store bakeries, and small local bakeries. Commercial bakeries operate at a national or regional level, and deliver bread products to supermarkets through two channels: fresh or frozen. Most bread is sold fresh and stocked by the bakeries themselves in the bread aisle at the super market. Frozen bread products are baked, frozen, and delivered to the store for sale in the freezer sections. In-store bakeries bake fresh bread at the supermarket and typically sell it in the deli section. By contrast, local bakeries often operate their own stores and frequently market through alternative channels, such as farmers' markets and local shops. King's Hawaiian occupies a unique space in the channel. They ship their breads frozen to supermarkets through a third-party logistics operator, where store employees thaw and display it in the deli section.

Bread has long been a staple of the American diet, but the market over the past five years has diverged. Health conscious consumers demand more nutritious products, leading many producers to expand production of specialty offerings at premium prices. Additionally, demand for artisanal offerings from retail bakeries has grown dramatically. At the same time, major commercial producers, such as Flowers Foods and Bimbo Bakeries, have experienced low sales growth and even declining sales, driving them toward acquisition as a growth strategy. For large operators, declining sales of traditional white bread can be offset by increasing demand for healthier and artisanal products with higher margins.

In 2000, there were eight major commercial bread product producers. By 2015, consolidation left three large operators: Grupo Bimbo (operating as Bimbo Bakeries in the US), Flowers Foods, and Pepperidge Farms (Flowers Foods, 2015). These top three firms will account for an estimated 26\% of industry revenues in 2015. Their growth has been driven primarily by acquisitions (Table 1). Many operators produce geographically confined or artisanal offerings that are difficult for large operators to offer on a national scale. It is predicted that market concentration will increase as large operators acquire smaller producers. Additionally, as large manufacturers produce more specialized and artisanal offerings, smaller operators will shut down due to competitive pressure. Currently, there are an estimated 5,280 enterprises employing fewer than nine people. While barriers to entry are low, competition is high and the number of new operations is expected to grow at only $1.9 \%$ per year through 2020 . Thus, new operations might not open at the replacement rate for those that are purchased or shut-down, and increasing market concentration will be a key feature of the industry over the next decade.

Table 1. Bread products industry (adapted from Grupo Bimbo, 2014; Yucel, 2015).

\begin{tabular}{lllll}
\hline & Industry total & Bimbo Bakeries & Flowers Foods & Pepperidge Farms \\
\hline Revenue & $\$ 42$ billion & $\$ 4$ billion & $\$ 3.7$ billion & $\$ 900$ million \\
Bread product market share & $100 \%$ & $15.4 \%$ & $9 \%$ & $2.1 \%$ \\
Fresh bread market share & $100 \%$ & $30.5 \%$ & $13.9 \%$ & $5.9 \%$ \\
Employees & 194,000 & 22,000 & 10,300 & 4,000 \\
Bakeries & 9,000 & 60 & 47 & 9 \\
Acquisitions & N/A & Mrs. Baird's & Earthgrains, & N/A \\
& & Bakeries, & Hostess Breads, & \\
& & Pacific Pride, & Tastykake Baking & \\
& & Sara Lee & & \\
\hline
\end{tabular}


For fresh, packaged breads, the market is dominated by the big three operators. As of April 2015, Bimbo Bakeries had an estimated 30.5\% of the market, Flowers Foods had 13.9\% and Pepperidge Farms had 5.9\%. The remaining market is divided between independent enterprises, which account for $23.2 \%$ of industry revenues, and store brands, which account for $26.5 \%$.

While King's Hawaiian manufactures round and sliced breads and sandwich buns, together they currently account for less than $20 \%$ of sales revenue. The majority of the company's sales are dinner rolls, primarily their Original Hawaiian Sweet Dinner Rolls, but also their Honey Wheat and Savory Butter rolls (Figure 4). While all the major bread industry companies produce dinner rolls, King's Hawaiian has little national, direct competition in the sweet Hawaiian roll category. While Sara Lee produces a sweet Hawaiian roll, it is significantly less popular than King's Hawaiian's. Competition for sweet rolls comes primarily from supermarkets' in-house bakeries and from small local producers.

Given the nature of the market, efficiency and cost control are essential for operators to maintain margins. Industry wide, operating profit, or earnings before interest and taxes, is expected to be $4.6 \%$ of industry revenues for 2015. The primary drivers of margin volatility are fluctuations in input prices for primary ingredients: wheat flour, sugar, eggs, and dairy. Additionally, changing consumer tastes for premium products and artisanal offerings, and changing preferences for healthier options, have placed greater pressure on operators. While many artisanal or healthy products can command higher margins, they also place pressure on operators to adapt quickly and market products effectively. Large operators, such as Bimbo Bakeries or Flowers Foods, are able to pass on some costs to retailers or consumers through market pressures and brandloyal customer bases. Large operators also are able to engage in commodity hedging, diversify suppliers, and distribute production geographically to meet changing demands. Small enterprises are caught between volatile inputs and demand, making margin protection even more challenging. Overall industry profitability is expected to be stable over the next five years, and may rise as operators adjust to new consumer demands for higher-margin products.

Success in the industry is dominated by three factors: innovative and differentiated products, marketing and brand establishment, and cost controls. As demand changes for healthier, artisanal, and premium products, operators increasingly need to invest in developing new and differentiated products. These higher-margin products can command premium shelf space and may be able to expand into new distribution channels, including restaurants and coffee shops. However, they require greater marketing and branding efforts to build recognition and sales volume. Branding and marketing are critical in this industry to acquiring premium shelf space from retailers and attracting and retaining loyal price-insensitive consumers. Industry wide, marketing will cost an estimated $2.3 \%$ of revenues in 2015 , and will be higher for larger operators.

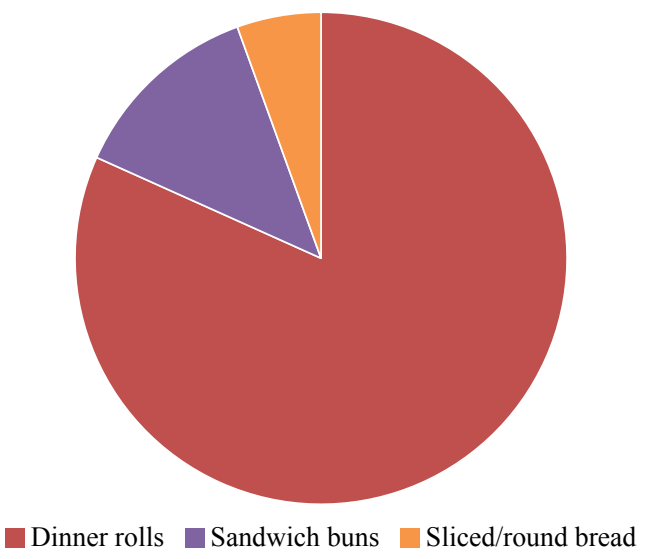

Figure 4. King's Hawaiian revenues by product category. 
Cost control is more challenging. While small operators might be able to brand and market effectively over a limited geographic region, they have no control over commodity prices. Large operators have diversification and financial strategies to manage raw material costs over time. The most common are term contracts for delivery at fixed prices, financial hedging strategies, geographic diversity in suppliers, and the use of multiple suppliers for each input. The future may bring an increase in the use of partnerships with suppliers, particularly as artisanal and premium product production requires more specialized or unique raw materials. This has been particularly true as operators alter recipes by using more expensive materials to meet increasing demand for healthier options and higher quality. Input costs for the industry are expected to account for more than $46 \%$ of revenues in 2015 (Yucel, 2015).

Distribution also represents a significant cost and challenge to industry operators. The geographic dispersion of production and significant investments in distribution are heavily driven by the fresh, perishable nature of the bread products that dominate industry sales. Small operators might have distribution costs, depending on their retail arrangements. Large operators always face distribution challenges. The primary downstream markets for large industry operators are supermarkets and grocery stores, and food service, hospitality and institutional entities. Large operators typically use their own distribution networks to deliver products from bakeries to retail, food service, and wholesale operators. Bimbo Bakeries and Pepperidge Farms have access to nearly $100 \%$ of American consumers through their distribution networks. Bimbo Bakeries uses its own fleet of delivery vehicles to distribute its products and also contracts heavily with independent distributors. Flowers Foods estimates that as of 2014 it serves over $80 \%$ of the US population through direct to store delivery, primarily using its own distribution network. Pepperidge Farms accesses the US retail market through Campbell's Soup's North America Foodservice operating segment, the distribution subsidiary for the firm, and its distribution is heavily integrated with other Campbell's Soup Company products. Pepperidge Farms also uses independent sales distributors, which the company supports in purchasing routes by guaranteeing bank loans from third party financial institutions (Campbell's Soup, 2014).

\section{Operations at King's Hawaiian}

King's Hawaiian uses four major raw materials to produce its indulgent Hawaiian breads: wheat flour, butter, eggs, and sugar. In addition, the firm uses a variety of minor and micro ingredients, such as yeast and enzymes, which, among other attributes, help stabilize the bread for frozen storage and distribution and improve shelf life.

Production begins with raw material selection. While King's Hawaiian has used the same materials from the same suppliers for decades, Dan said, 'there was no clearly defined input strategy for many years. We just locked in prices when suppliers recommended it'. This worked for a family-run, entrepreneurial firm with excellent supplier relationships, but it was becoming a problem for a fast-growing, professionally managed firm. The unique Hawaiian bread products require somewhat interchangeable butter and egg supplies; however, the wheat flour needs to be within highly constrained specifications. It is the only raw material for which the company still has only one supplier due to the uniqueness of the flour. King's Hawaiian uses a farinograph to test the flour for various attributes, including absorption, stability, and tolerance. Because the wheat is grown and currently milled in the Pacific Northwest, the flour travels a significant distance to reach the production facilities in California and Georgia. When the flour arrives out of specification, it can require significant effort to rework the production process in order to alter the applications of time, water, or temperature to maintain high quality output. These efforts can come at such expense, or finished goods quality impairment, that the company will also refuse the flour shipment when it arrives too far out of the required specifications, at which point the miller may sell the flour locally at a discount. The greatest challenges to flour quality are travel time, heat, and humidity. Generally, flour is used within thirty days of milling. Torrey and the baking science team have been working to qualify flour milled in Georgia and California by the same supplier using the same wheat. The ongoing process requires significant testing. 
Suppliers for butter, sugar, and eggs are more fungible than flour, and Dan and Torrey have found and qualified at least two sources for each of them. Butter, sugar, and egg input management focuses on cost control, contracts, and risk mitigation. Butter, which has been historically supplied by a California dairy cooperative, and recently from a new, regional source for the Georgia operations, experienced significant price volatility in 2014 (Figure 5). King's Hawaiian's long-standing relationships with its suppliers helped to navigate the challenges, but not without significant pressure on profit margins. Sugar is highly interchangeable and sourcing it poses few challenges to the firm. Alternatively, during the avian influenza outbreak in 2015, the company faced significant egg supply challenges. Steve said, 'avian flu dried up 500,000 pounds of eggs overnight' when one of the super-producers went down. That left Steve and Dan facing a crisis: what do you do when one or more of your major suppliers invoke the force majeure clause in the contract?

Contracts for all major raw materials are negotiated multiple times per year. Excluding distribution, raw materials make up more than $40 \%$ of the cost of goods, the largest of any category. Overhead, packaging, and direct labor make up the remaining $60 \%$ of the cost of goods. These numbers are generally in line with industry averages, but because King's Hawaiian makes a premium product with higher raw material quality standards, their supply chain faces greater potential volatility. In the past, the company managed these challenges through close relationships. 'We are comfortable being very close to our suppliers', Steve said. 'We treat them as partners. Mark wants to share our strategic plan with them and, in turn, we want to see their strategic plans. That way everyone knows what the future holds'. The relationship focus extends beyond crises; it is instrumental in the way the firm operates every day.

Generally, raw material delivery to the production facilities is managed by the suppliers. Flour and sugar are delivered from the train yard to the facility by trucks, which take three hours each to unload into three, 110,000 pound silos. With three to five daily deliveries, scheduling truck arrivals is critical to managing the flow of raw materials. Micro ingredients, along with eggs and butter, are delivered as pallets or super bags and are stored until added to the mixing system. In general, King's Hawaiian keeps only a few days of ingredients on-hand. From the silos for flour and sugar and the controlled dump stations for eggs, butter, and the minor and micro ingredients, the raw materials are delivered to the mixing room. Along the way, the ingredients go through computer-controlled measuring processes to get exactly the correct blend in the

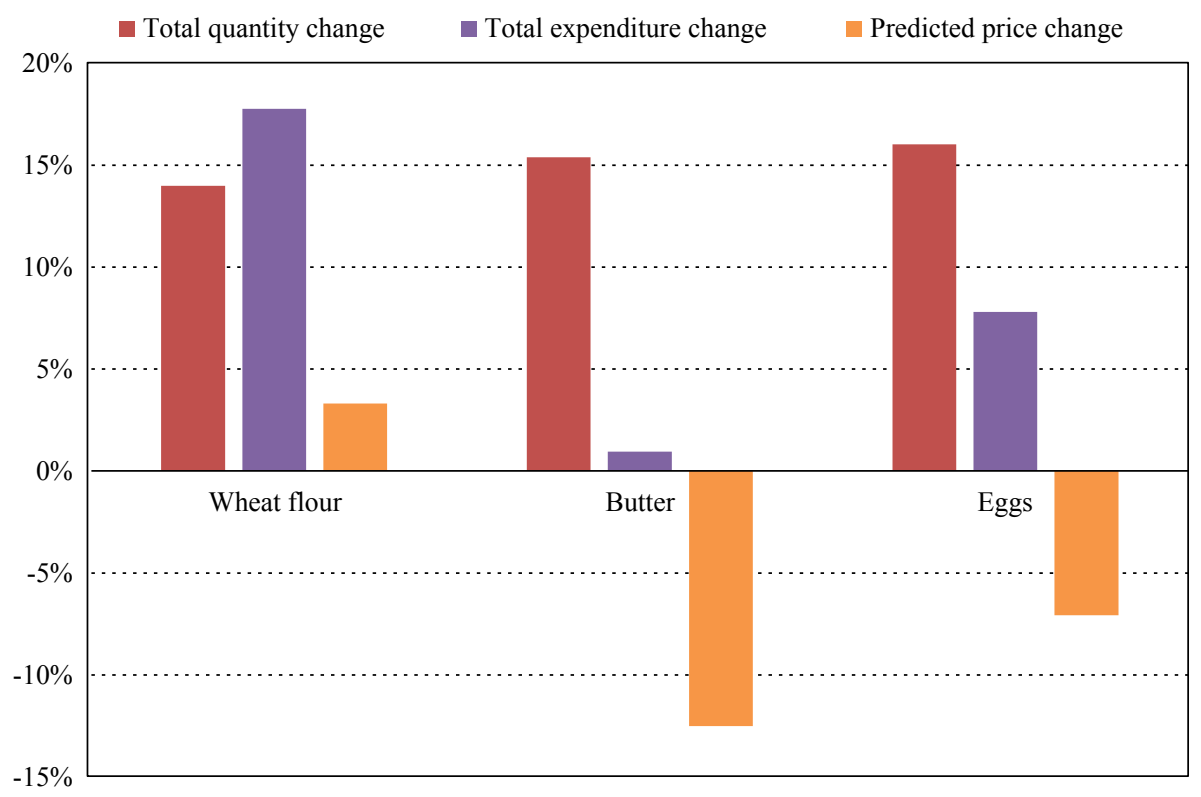

Figure 5. King's Hawaiian predicted raw materials quantities pre-avian influenza outbreak, expenditures, and price changes, 2014-2015. 
mixing room. The Torrance facility uses a batch mixing process, while the Oakwood facility uses a continuous mixing process, which is faster but also more sensitive to raw material attributes. To maintain the secrecy of the recipe, the mixing room is separated from the rest of the baking facility and has controlled access. From the mixing room, the dough is dropped onto the processing lines where machines shape, quality check, and proof it. Employees are stationed along the line to monitor for quality and ensure smooth operations. Both the California and Georgia facilities are capable of making most of the products offered by King's Hawaiian, but changing the production run requires time to reset the lines. For flexibility, the lines are made with interchangeable equipment for multiple products. A line making sliced bread on Monday could be making twelve-packs of dinner rolls on Tuesday.

After baking, the bread is conveyed from the production room, through the slicing machines (if necessary), and into the packaging room. Packaging is the most labor-intense part of the process and is also the final quality check. Packaging employees are carefully trained to look at conformity, color, and size and to discard any finished product not meeting the exact specifications laid out by Mark. The final quality check is a critical part of the process, and at this stage, the company loses between 10 and $15 \%$ of final products out of quality concerns. Mark stated, 'We have a brand promise to our consumers to deliver irresistible goods at a high level of quality...everyone is ensuring that only the best product possible is getting out of our facility'. Products other bakeries would be willing to sell in premium marketing channels might be rejected by King's Hawaiian's stringent quality standards.

After packaging, the products are packed into cases and sent to shipping. One of King's Hawaiian's most important strategic differentiators happens during transport. The fully baked, finished breads are picked up by third party logistics providers in freezer trucks and frozen during transport. They are taken to third-party frozen storage facilities where they wait for distribution to supermarkets. The frozen delivery model is not only built into the recipe, it gives King's Hawaiian the ability to maintain a national footprint by operating two large bakeries instead of dozens of smaller ones. But it comes at a cost. While the company maintains excellent supplier relationships, they have had some difficulty building long-term partnerships with distributors. King's Hawaiian pays for frozen storage and distribution on a monthly basis based on expected inventory levels. Because they pay in advance, even when they do not use all of their allocated space, they must still pay for it. For this reason, distribution makes up almost $20 \%$ of the total cost of goods sold - higher than the industry average.

Despite its costs, the frozen delivery model permits an advantage beyond consolidated production: inventory stockpiling. Due to the seasonality of King's Hawaiian's sales, the company would be unable to produce enough fresh product to meet demand at its peak. Depending on the season, the company can have anywhere from $\$ 15$ to 30 million in finished goods inventory. Despite this, King's Hawaiian takes up only a small part of the third-party distributor's capacity. Frozen storage allows for production smoothing to meet demand. The company can start producing at higher levels in late summer and early fall to meet the huge holiday increase in sales. Consistent output levels demand consistent raw material levels, so the distribution model has benefits to managing the raw material supply chain.

What the company gives up in control by relying on third-party logistics providers it regains with marketing savvy. The traditional bread aisle in supermarkets is stocked and maintained by the bread manufacturers themselves, who purchase the retail shelf space. King's Hawaiian, however, generally has its products delivered to supermarket deli sections, where the deli staff stock and manage them. King's Hawaiian avoids the need to operate its own distribution and stocking staff. In exchange, the company offers supermarkets slightly higher retail margins than other bread companies, giving the deli manager incentive to maintain and display King's Hawaiian products. Additionally, by selling the indulgent Hawaiian breads through the deli department, consumers perceive the products as higher quality than competitors.

From raw material selection and production, to distribution and marketing, the entire process is designed to create the highest quality products possible. King's Hawaiian, and Mark Taira, have invested significantly in 
developing scientific processes, but have still maintained the artisanal mindset. Creating indulgent products and 'sharing more aloha spirit' on a large scale has challenges, but the company has implemented processes that maintain the quality expected by the Taira family, even as the firm grows.

Looking ahead, some serious questions remain. As articulated by Chad Donvito, the brand general manager, 'we know we can sell it, but there are things we need to put in place now to be able to produce enough to meet demand in five years'. The greatest challenges to growth come not from King's Hawaiian's ability to produce or sell its products, but from its ability to strategically manage its supply chain.

\section{The supply chain: flour, butter and eggs}

King's Hawaiian uses a variety of top quality ingredients. Of the four primary ingredients in their recipe, flour, butter, and eggs are the most challenging with respect to supply chain and risk management.

\subsection{Flour milling}

The modern milling industry is characterized by stable company numbers, established processes and technologies, low-margin products and brands, and revenue that increases at the pace of the broader economy. The industry is deeply mature and operators in it grow primarily through mergers and acquisitions.

Flour milling in the United States broadly covers activities of milling grains and vegetables into flour. It also includes cleaning, polishing and milling rice, and producing malt from cereal grains. Generally, milling operators purchase supplies, including wheat, barley, rice, corn, and soybeans, directly from producers or through wholesaling operations. The industry as a whole is expected to generate $\$ 21.9$ billion in revenues in 2015, and IBISWorld (Yucel, 2015) predicts annualized growth of $2.4 \%$ through 2020. Wheat flour dominates industry output and will account for $44.5 \%$ of total industry revenues in 2015. The USDA (2013) estimated that in 2011, Americans consumed approximately 132.5 pounds per capita of wheat products, including breads, pastas, and pizzas.

Food manufacturers, such as King's Hawaiian, account for $24 \%$ of industry revenues. This revenue stream is second only to grocery wholesalers that distribute flour to supermarkets and other direct-to-consumer retailers, which account for $26.6 \%$ of industry revenues. Additional market segments include the food service industry, exports, and breweries. Export markets account for $12.7 \%$ of revenues; however, export growth is expected to be slower than industry growth due to capital asset globalization and trade barriers.

Flour milling has moderate barriers to entry due to high initial and ongoing capital requirements, so firms seek economies of scale in operations to reduce unit costs. Thus, firms in the industry are high-volume, lowmargin operators. In addition, large firms are often vertically integrated, either as owners or subsidiaries of bakeries or crop production and origination organizations. Given that keys to success in the industry include stable supply and distribution contracts and the ability to pass input-cost increases to the customer, vertical integration helps firms more effectively manage margins. Joint ventures are also becoming more common. In 2014, for example, ConAgra Foods, Cargill, and CHS created a joint venture named Ardent Mills to manage all of the firms' North American flour milling operations (Streetinsider, 2014). The joint venture now has more than 20\% market share, followed by Archer Daniels Midland with 8.7\%. An additional merger announced in 2014 created Grain Craft, the result of a deal between Milner Milling, Pendleton Flour Mills, and Cereal Food Processors, all privately held, family-operated firms. Grain Craft operates 16 flour mills in 11 states, including the Pacific Northwest, southern California, and Georgia, and supplies King's Hawaiian's unique flour. As a new firm at the national level, Grain Craft is trying to establish its market niche and gather business from large, national flour users. They work closely with King's Hawaiian to meet the firm's needs, particularly as King's Hawaiian is growing so quickly. But the stringent flour specifications pose challenges. After all, wheat is not a homogeneous commodity. 
According to the USDA, the five major classes of US wheat are hard red winter, hard red spring, soft red winter, white, and durum (USDA, 2013). Generally, each class of wheat has a geographic footprint over which it best grows. Regional soil and weather differences provide specific attributes to the wheat, impacting the qualities and characteristics of its flour. Given the geographic distribution of wheat production, transport is a significant factor in manufacturing, particularly for firms that have specific or unique needs. Grain Craft currently manages transport by train for King's Hawaiian's milled flour from the milling facility in the Pacific Northwest to the bakeries in California and Georgia.

Domestic wheat prices can be somewhat volatile, but generally less so than global prices. The world price of wheat is subject to fluctuations based on the behaviors of various countries, such as Russia's 2010 export ban, and to the relative value of the US dollar. As the US dollar strengthens, it places downward pressure on global prices and reduces export demand for US wheat. In recent years there has been a significant appreciation in the dollar, with moderate downward pressure on domestic wheat prices (Figure 6 and 7).

Firms in the flour-milling industry manage price risks through contracts and financial operations to minimize the impacts of price volatility to margins. Generally, when wheat prices increase, firms in the milling industry are able to pass on costs to customers and consumers.

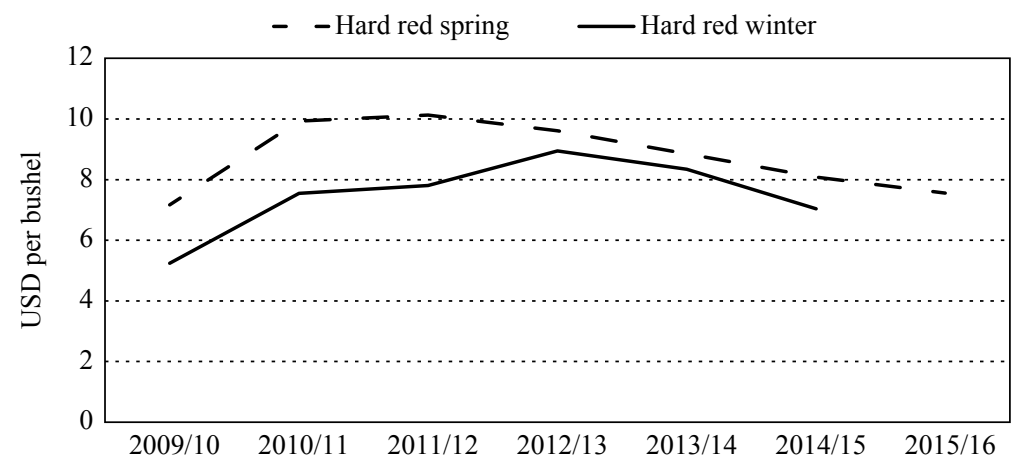

Figure 6. Wheat prices (crop year averages USD per bushel) (adapted from USDA National Agriculture Statistics Service, 2015; prices for Kansas City, MO, USA).

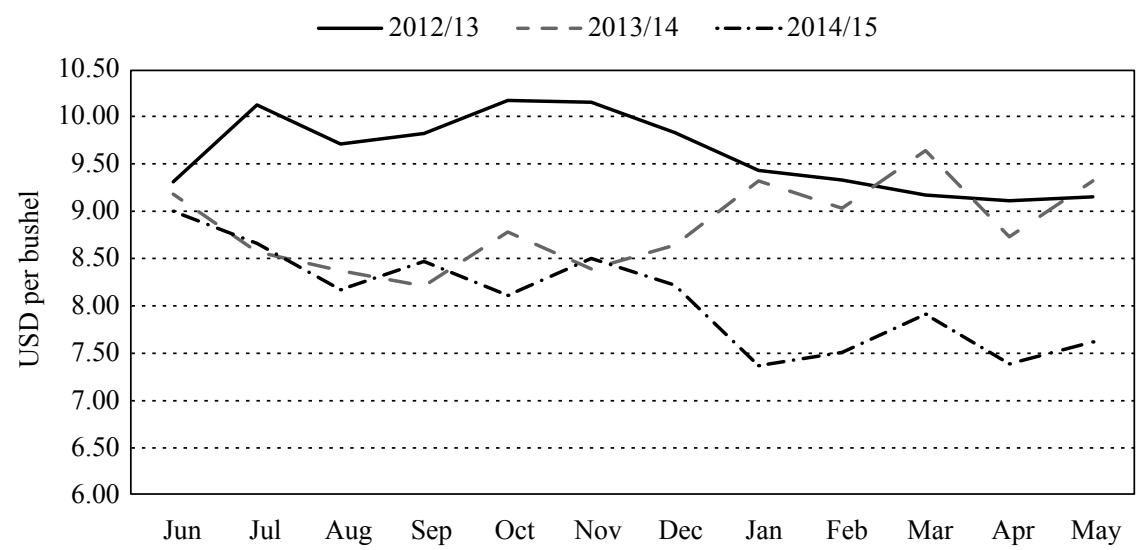

Figure 7. Crop year volatility: hard red spring variety (USD per bushel, monthly averages) (adapted from USDA National Agriculture Statistics Service, 2015; prices for Kansas City, MO, USA). 
This arrangement leaves downstream firms dependent on contracts to manage prices and margins. It also encourages relationship development with flour millers. Generally, success for flour-milling operations depends not only on the ability to pass on costs, but also in generating economies of scale and scope, and offering differentiated products to meet broad downstream market needs. Many specialty bakeries, such as King's Hawaiian, require unique flours with specific characteristics. This encourages bakeries and bread manufacturers to develop relationships with milling operators and to work closely with them to meet their needs.

Grain Craft, like many of King's Hawaiian's suppliers, has been willing to work with the company to meet its needs - even when that requires refused flour shipments or high levels of scrutiny. Dan attributes this to King's Hawaiian's market position and growth, and also to Grain Craft and King's Hawaiian's desires to be strategic, long-term partners. This has not, however, kept Dan and Torrey from seeking bids from other flour millers. Torrey believes that the 'millers could be more responsive' to fix some quality issues, and Dan is insistent that 'single-point failures be eliminated' from the risk-matrix. These challenges created two new goals for Torrey: qualify the current flour supplier's California and Georgia mills so that milled flour does not travel as far; and, qualify an additional flour supplier. Torrey believes that reduction in transit time and addition of new sources will help improve quality and mitigate risks.

\subsection{Dairy production and butter}

Dairy production in the United States is a highly dispersed, $\$ 35.6$ billion industry. Revenue for dairy producers is highly volatile, driven primarily by the price of milk, demand from dairy product production, and feed prices. Approximately two-thirds of milk is sold as manufacturing milk to make cheese, yogurt, condensed and evaporated milk, powdered and dry milk, and butter. Dairy processing is a $\$ 114$ billion industry, and is highly mature, competitive, and slow-growing, with projected annual growth of just $0.4 \%$ between 2015 and 2020. Creamery butter, one of the primary ingredients used by King's Hawaiian, will account for only $2.6 \%$ of the industry's revenues for 2015 .

King's Hawaiian's butter use has grown significantly as the company has grown. Its primary butter suppliers are the California Dairies cooperative and Dairy Gold. California Dairies has been supplying King's Hawaiian for many years, while contracts with Dairy Gold were added to mitigate supply chain risks as the firm grew. King's Hawaiian uses typical butter, such as that purchased by consumers at the grocery store; however, unlike most commercial bakeries, the company uses salted butter in its products, which is not necessarily substitutable for a combination of unsalted butter and salt. The butter is generally purchased on six-month contracts that are negotiated three to four months in advance. Due to their relationships with California Dairies and Dairy Gold, the company has some flexibility regarding contracted volumes. King's Hawaiian is able to purchase what they need at the contracted rate even when total volumes are more or less than specified by the contract. In 2014, King's Hawaiian used almost 10 million pounds of butter, with an average annualized price of approximately $\$ 2.11$ per pound. Butter price volatility was challenging to King's Hawaiian's margins in 2014 as prices increased from $\$ 1.55$ per pound early in the year to $\$ 3.06$ per pound by September. With the opening of the second Oakwood line and increased consumer demand for their products, King's Hawaiian estimates their 2015 butter purchases will increase by more than $15 \%$, to nearly 11.5 million pounds. But lower butter prices in 2015 mean that the company estimates only a 1\% increase in total butter expenditures for the year, with an average estimated price of $\$ 1.84$ per pound. In 2015 , butter purchases are expected to cost $6 \%$ of gross sales, down from $7 \%$ in 2014 . This $1 \%$ change not only reflects increasing sales but also declining butter prices, and has a large impact on the bottom line margin. Similar to many agricultural products, the unpredictability of butter prices makes contracting and planning difficult (Figure 8).

California Dairies and Dairy Gold typically manage the deliveries to King's Hawaiian's Torrance locations. Butter for the Oakwood plant is transported across the country, which California Dairies also manages. This arrangement has been challenging and, as such, the company has started sourcing butter from a regionally based producer to supply some of the demand for the Oakwood operations. One of the primary challenges for 


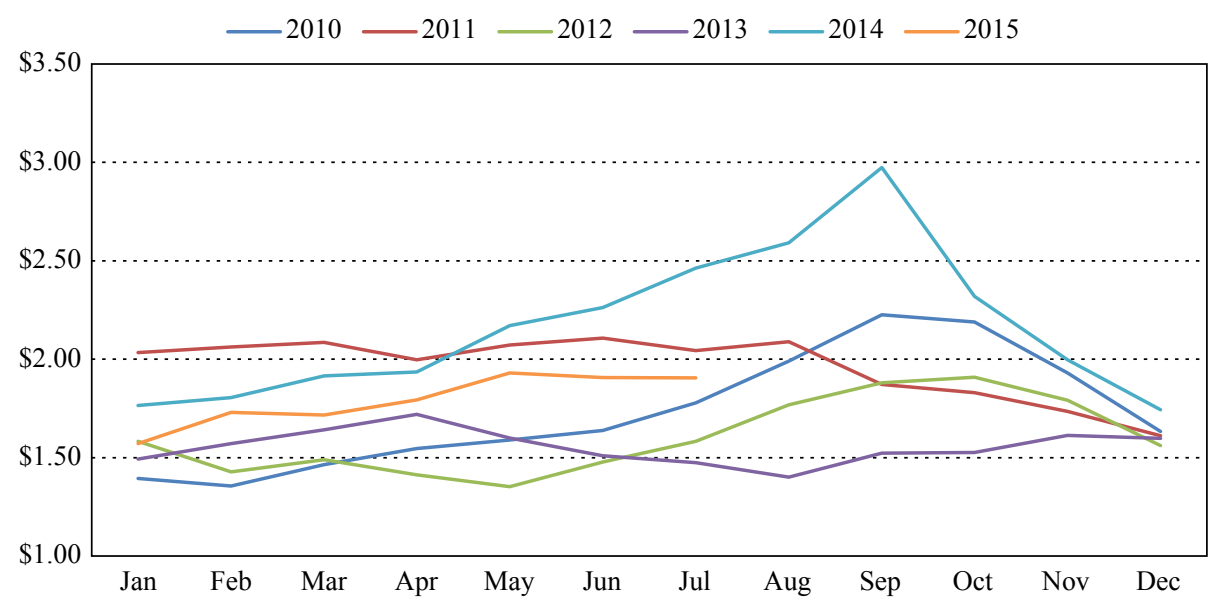

Figure 8. Five year price of butter (dollars per pound by month) (adapted from Chicago Mercantile Exchange, 2015).

butter transportation is the need for it to arrive at the production facilities at a specific ambient temperature, which increases transportation costs over long distances.

Despite some volatility in the price of butter, it is broadly available, and a moderately substitutable ingredient in King's Hawaiian's production process. This has made it comparatively simple to add new sources for the Oakwood expansion, and for the recent addition of Dairy Gold as a supplier.

\subsection{Egg production}

US egg production is heavily concentrated in the Midwest, with Iowa, Ohio, Indiana, Pennsylvania, and Texas having the highest numbers of laying hens. These states represent an estimated $47 \%$ of all US laying hens (American Egg Board, 2015). Historically, eggs were produced locally or in 'backyard systems' for consumption by farmers or sale at local markets. As specialization and technology advanced, the egg-laying industry developed into concentrated, sophisticated mega-operations.

The highly concentrated nature of the industry has led to serious challenges, primarily with avian influenza, which devastated hen populations in 2015. Starting in mid-December 2014, the USDA began tracking several ongoing outbreaks of the disease along the Pacific, Central, and Mississippi flyways. Prior to this, avian influenza had only affected commercial poultry three times: in 1924, 1983, and 2004. Since the first report in December 2014 of the most recent outbreak, more than 48 million birds have been affected (USDA, 2015c). The geographic clustering of farms along migratory flight paths for wild birds is blamed for the outbreak (USDA, 2015b). The impacts of the egg shortage were felt nationwide due to the Midwestern concentration of egg farms. Between May 1 and July 1, hen populations dropped 9\% nationwide.

King's Hawaiian uses powdered eggs as one of the primary ingredients for its breads. In 2014, the company used more than 3.5 million pounds of powdered eggs, which required approximately 260 million fresh eggs. As production expands, the company expects powdered egg use to increase in 2015 to more than 4 million pounds. In 2014, King's Hawaiian spent an average of $\$ 3$ per pound for powdered eggs, and had predicted that prices would decline approximately $7 \%$ for 2015 . Unfortunately, as of June 2015, the average national price for dried eggs was $\$ 10.17$ per pound, up 145\% from the June 2014 average of \$4.17 (USDA, 2015a). The huge increase has significantly challenged King's Hawaiian's margins and even forced the company to slightly raise output prices to compensate.

Prior to the avian influenza outbreak, King's Hawaiian had supplier relationships with three out of the country's six largest egg producers, including Rembrandt Eggs, their primary supplier. At the time Dan was hired, the company used only one egg supplier. As part of Dan's mission to diversify the supply chain, he 
sought out new contracts and worked with Torrey to qualify new sources. The contracts negotiated for the second half of 2014 called for delivery of almost 2.3 million pounds of powdered eggs, in contracts with three producers for 1.4 million, 500,000, and 400,000 pounds. There is no market for hedging egg prices, thus purchases are subject to market prices, contracts, and 'black swan' events. When markets shift or dramatic events cause supply shocks, purchasers have little compensation. As Steve said, 'there can be some risk of not having enough eggs, but there is also a price challenge. Can you just open your checkbook?'

Despite Dan's work to add suppliers, and the three major contracts they had in place, it was only after avian influenza struck that he and the leadership team realized the extent of the challenge to King's Hawaiian. 'When you have huge, vertically integrated operations with more than 5 million birds and disease strikes, the market dries up,' Dan said. '500,000 pounds of eggs disappeared over night. What can you do when a producer invokes the force majeure clause in a contract?' The leadership team had made efforts to diversify suppliers, but as avian influenza was decimating flocks across the Midwest, Dan and Steve realized, 'We still had not really diversified. If we had known most of our eggs came from Iowa, we would have rethought our sourcing'. The majority of King's Hawaiian's eggs were sourced from Iowa, directly under the flight path of the migratory birds spreading the disease (Figure 9).

As soon as Dan received the call from one of their major suppliers, he started working through his contacts list. The challenge was not only to find new supplies at manageable prices, but to get started before other firms in the same position discovered their supplies were also gone. Dan decided to make the trip to the Midwest. 'I was driving a pick-up all over trying to find new suppliers,' he said. 'Anybody who could provide dried eggs was on my list. We had trouble getting people to call us back'. Dan and John Linehan were able to work with the State of Georgia to get producers there to return calls, and eventually the leadership team had located enough eggs to get them through the short-term. Not only did their relationship with Georgia help, the company's long-standing, primary egg supplier worked closely with them to lessen the impact of the egg shortage on their financial results. This included assisting King's Hawaiian in locating alternative sources and ensuring sufficient quantities to maintain production. 'We have a very supportive relationship with our primary supplier, who really helped through this,' said Steve.

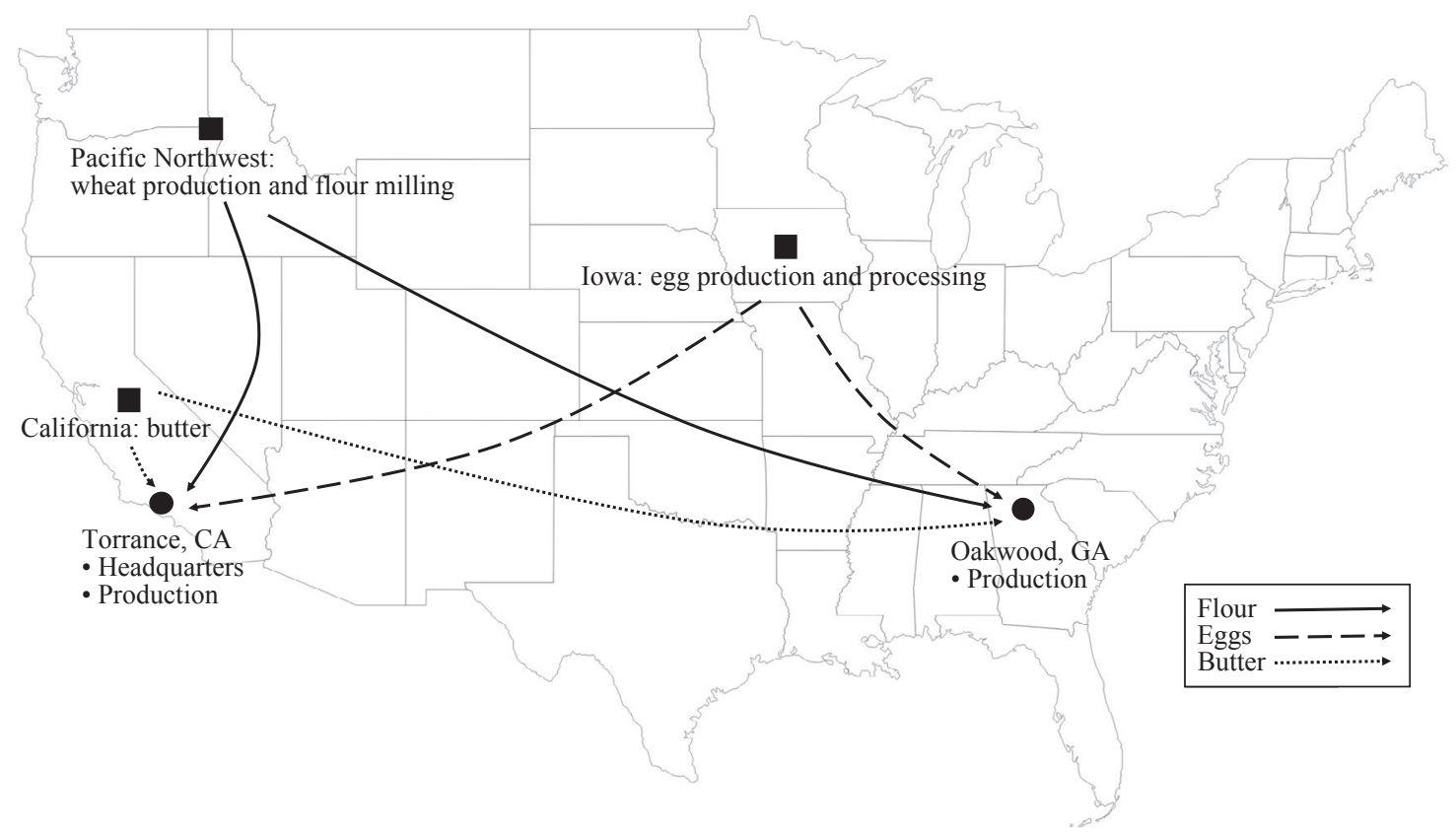

Figure 9. Map of sources and destinations for major ingredients. 
The challenges are not over, though, and King's Hawaiian is exploring every possible avenue to create opportunities from the difficult situation. With support from their primary supplier, who has operations in the Netherlands, they have even explored importing dried eggs. In June, the USDA's Food Safety and Inspection Service announced that dried eggs could be imported from the Netherlands, the first time in over a decade that US firms could import European eggs. But the solution is only temporary. While some producers may decide to find substitutes or alter their recipes, that approach is not an option for King's Hawaiian. Changing the formula or using substitutes changes the flavor, texture and other characteristics of the product and makes the dough very difficult for the company's equipment to handle. Steve, Dan, and the entire leadership team are working to find a long-term solution to diversify their risks and manage their raw material costs. 'It's definitely putting pressure on our margins,' Steve said. 'We have to find a way to compensate for the high egg prices today while planning for growth tomorrow'.

\section{Facing challenges and growth at King's Hawaiian}

The growth at King's Hawaiian has been phenomenal and stressful for the leadership team. The company's transition to a professionally managed organization has been guided by Mark Taira's strong focus on people and long-term planning. The culture of excellence, dignity, and 'telling it like it is in a way that can be heard' has helped the leadership team foster strong communications and a deep connection to shared success. Growth at King's Hawaiian has been challenging, and the butter and egg crises have helped expose risks the firm needs to face in order to become a billion-dollar company. 'When any business looks at growth, there is always risk,' Mark said. 'It's just a matter of how you manage that risk. If you look at the history of our company, we're not big risk-takers. We take risk appropriately for our growth. As I look at things, it's always about the long-term' (Gorton and Malovany, 2014).

The real challenge faced by a fast-growing, food manufacturing firm with a hugely popular product goes beyond its ability to manage production or grow facilities, but is in the ability to manage and grow their supply chain while still maintaining high quality. Importantly, as a family-owned operation, the company can focus on long-term opportunities, sometimes at the expense of short-term gains. 'We are not a bread company,' Steve reiterated. 'We are a Hawaiian foods company'.

While the company makes bread today, they have a broader focus to build a holistic brand image. One major differentiation from their competitors is their focus on high quality ingredients: they do not use oils, margarines, or corn syrup or switch ingredients for lower priced substitutes. As John said, 'At the core of everything we do are our brand promise, behaviors, and mission'. This cultural imperative will drive everything the firm does as it opens up the Hawaiian foods market in new geographies and new products.

The quality focus extends beyond their desire for consistent finished products. The company wants to build a brand that precludes market space for imitation products. To do this, they focus on providing indulgent products for every household, every day, while maintaining an artisanal mindset toward their products. Supply chain management is integral to the future of the brand proposition, particularly as the leadership team considers new opportunities.

Beyond increasing household penetration to more than $45 \%$ and increasing annual purchase frequency to between six and seven, King's Hawaiian's leadership team is considering expanding their product line. The company views bread as an introduction for consumers into the Hawaiian foods category, and product line expansion, such as a line of barbecue sauces, is an attractive next step. But product expansion brings challenging questions about what the company needs to look like in the near future to make the leap. 'What kind of structure does the company need? What can we do today to make that a reality?' Steve asked. Supply chain management questions weigh heavily on the minds of the leadership team.

Managing raw materials on a national scale is challenging. The expansion into Georgia was a lesson in managing growth across large geographies. The Torrance, Calif. bakery took 31 months to complete, while 
the Georgia facility required only 7.5. 'That gives you a benchmark on how we improved,' John said (Gorton and Malovany, 2014). However, the firm was able to continue using its current suppliers for the Georgia expansion, while slowly building relationships with new suppliers in the region. Changes to the supply chain were logistical rather than qualitative. New products might require entirely new supply chains and new management processes. This thought, for the leadership team, brings Steve's questions back into sharp focus: what does King's Hawaiian need now to make the leap to new Hawaiian food products over the next decade? How can crises be turned into opportunities? What can King's Hawaiian do to proactively manage its supply chain to keep the company on its high growth path?

\section{Discussion questions}

1. Suppose you were tasked with analyzing King's Hawaiian's supply chain:

- create a diagram of the firm's supply chain;

- identify the risks in the supply chain;

- determine which elements of the supply chain distinguish King's Hawaiian from its competitors. Are they strengths or weaknesses?

2. What should King's Hawaiian do to reduce volatility, risk, and raw material variability in their supply chain?

3. What are the strategic supply chain options for King's Hawaiian, and how should they be prioritized?

4. What strategic recommendations do you have for King's Hawaiian as it continues to grow over the next 10 years?

\section{Acknowledgments}

The authors would like to thank the leadership at King's Hawaiian, including Steve Richards, Dan Raatjes, Torrey Nelson, John Linehan, and Mark Taira for their time and willingness to share their company with us. We would also like to thank Michael Boehlje, Gemma Berenguer, Mary Shelman, and Brent Ross for their comments and feedback.

Professor Allan W. Gray and Brian A. Bourquard of Purdue University's Center for Food and Agricultural Business prepared this case. Funding for the case was provided by the Center for Food and Agricultural Business, and not by the company. This case is for educational and discussion purposes and is not intended to demonstrate effective or ineffective management. This case is not a source of primary data and is not an endorsement of the subject company or its agents.

\section{References}

American Egg Board. 2015. About the US egg industry. Available at: http://tinyurl.com/yakggpe2.

Campbell's Soup. 2014. Campbell's Soup company 2014 annual report. Available at: http://bit.ly/1I3zxbU. Chicago Mercantile Exchange. 2015. Spot dairy prices, Chicago Mercantile Exchange. Chicago, IL, USA. Available at: http://tinyurl.com/y77qloxz.

Flowers Foods. 2015. Flowers Foods investor presentation. Available at: http://bit.ly/10e8N9q.

Gill, J. 2011. King's Hawaiian up and running in Oakwood. Gainsville Times. Available at: http://tinyurl. com/yd3mayg6.

Gorton, L. and D. Malovany. 2014. An irresistible aloha. Baking and Snack, October, 2014. Available at: http://tinyurl.com/ybz2fhhn.

Grupo Bimbo. 2014. Integrated annual report, April 10, 2015. Mexico City, Mexico. Available at: http:// tinyurl.com/ydyls5gj.

Posner, E.W. and A.N. Hibbs. 1997. Wheat Flour Milling. American Association of Cereal Chemists, Inc. St. Paul, MN, USA.

StreetInsider. 2014. Conagra Goods (Cag) completes Ardent Mills joint venture. StreetInsider. Available at: http://bit.ly/1CHw7em. 
United States Department of Agriculture (USDA). 2013. Wheat. Available at: http://1.usa.gov/1Spqlji.

United States Department of Agriculture (USDA). 2015a. Egg market news report. ISBN 1520-6122. Washington, DC, USA. August 2015.

United States Department of Agriculture (USDA). 2015b. USDA publishes updated interagency strategic and surveillance plans for avian influenza migratory birds. Available at: http://tinyurl.com/yby9nyus.

United States Department of Agriculture (USDA). 2015c. Update on avian influenza findings. United States Department of Agriculture, Animal and Plant Health Inspection Service, Washington, DC, USA.

United States Department of Agriculture, National Agriculture Statistics Service. 2015. Agricultural Prices. Washington, DC, USA. Available at: http://tinyurl.com/ybgutf4u.

University of Wisconsin-Madison. 2017. Understanding dairy markets. University of Wisconsin-Madison, Madison, WI, USA.

Yucel, I. 2015. Bread production in the US. IBISWorld industry report 3118.1 IBISWorld, Los Angeles, CA, USA. 